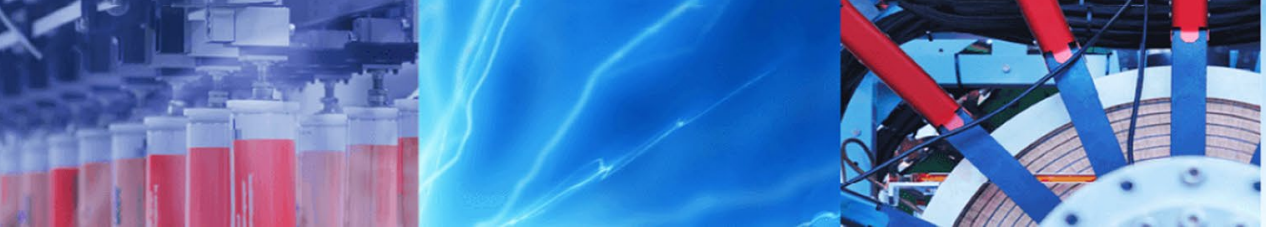

Research Article

\title{
CFD investigation of the effect of manifold and microchannel ratio on the hydrodynamic performance of microchannel heat sink
}

\author{
Yue Seong Ong ${ }^{1} \cdot \mathrm{Ku}_{\text {Zilati Ku Shaari }}{ }^{1}$
}

Received: 22 February 2020 / Accepted: 29 May 2020 / Published online: 11 June 2020

(c) Springer Nature Switzerland AG 2020

\begin{abstract}
Flow distribution of working fluid greatly affects the performance of microchannel heat sinks (MCHSs). Uniform flow distribution prevents the development of hot spots and dead zones. Major parameters that govern the flow distribution in MCHSs are manifold and microchannel geometry. Many studies involved complicated manifold designs or novel approaches which may not be easily incorporated. Also, many researchers have examined various microchannel geometrical parameters. However, simultaneous alterations of more than one parameter is scarce. The present study focuses on the effect of simple manifold layouts, namely rectangular manifold (Rect_MCHS), circular manifold (Circ_MCHS), and triangular manifold (Tria_MCHS), and microchannel geometry, defined by microchannel ratio, a ratio of microchannel width to microchannel spacing, on the hydrodynamic performance of MCHSs using three-dimensional computational fluid dynamic (CFD). The hydrodynamic performance of MCHSs was evaluated in terms of pressure drop, velocity distribution, and coefficient of flow nonuniformity. Results showed that higher inlet flow rates and smaller microchannel ratios produced better flow distribution performance in which the latter has a higher positive impact on the hydrodynamic performance of MCHSs. Smaller microchannel ratio designs have larger microchannel spacing which served as a barrier to create flow dispersion effect. This effect was further amplified at higher inlet flow rates. Generally, Rect_MCHSs produced the best hydrodynamic performance. Furthermore, variation in temperature showed negligible impact on the hydrodynamic performance of MCHSs, compared to inlet flow rate and microchannel ratio. This suggests that studies which concern with flow distribution performance could be conducted without the energy aspect to reduce computational time.
\end{abstract}

Keywords Microchannel heat sink · Microchannel · Manifold · Flow distribution · Computational fluid dynamic

\section{Introduction}

The advancement in microelectromechanical (MEM) technology and rapid development of integrated electronic technology have led to high-density packaging of multiple electronic components [1, 2]. Unfortunately, these devices tend to have thermal management issues due to complex processing and high workload. Temperature plays a crucial role in the operation of electronic devices. In fact, the reliability of an electronic device is an inverse function of its operating temperature [3]. Poor heat removal efficiency results in local overheating which damages or degrades the performance of the devices [4-7]. The concept of microchannel heat sink (MCHS) introduced by Tuckerman and Pease [8] is very promising due to the small geometrical dimension of microchannels. It offers many essential features, such as low volume per heat load, minimum coolant requirement, small device size, and large convective heat transfer coefficient $[9,10]$. On top of that, the heat dissipation capability of MCHSs also makes them suitable for highly specific applications that require compact heat removal solutions, such as biomedical process,

Ku Zilati Ku Shaari, kuzilati_kushaari@utp.edu.my; Yue Seong Ong, yue_17007965@utp.edu.my| 'Department of Chemical Engineering, University Teknologi PETRONAS, Seri Iskandar, Malaysia.

SN Applied Sciences (2020) 2:1199| https://doi.org/10.1007/s42452-020-2990-y 
telecommunications, metrology, cooling of high heat flux high-density microelectronics, nuclear reactor barriers, automotive industries, aerospace, fuel processing, and chemical industries [11]. In addition, green energy has gained significant attention in recent years. Uniform cooling is extremely important in high concentration photovoltaic module (HCPVM) to prevent hotspot, maintain long lifespan, and safety operation [12]. Furthermore, increase in temperature significantly reduces the conversion efficiently and therefore, the performance of the modules [13].

The flow distribution of working fluid greatly affects the performance of MCHSs [14, 15]. Uniform flow distribution prevents the development of hotspots and dead zones. This can be achieved with the aid of geometrical design [16] by ensuring the resistance of the distributed microchannels is the same, because the fluid takes the path of least resistance $[17,18]$. Furthermore, this contributes to better heat transfer performance, more effective temperature control, lower pressure loss, less pumping power, and minimization of flow-related vibrations, noise, stresses, and corrosions due to poor fluid distribution. These advantages translate into high reliability and durability of the equipment or devices [19-21]. In fact, Chein and Chen [9] showed that poor flow distribution resulted in severe temperature nonuniformity in the system. Furthermore, flow distribution plays an important role in many other applications, such as piping systems [22], chemical reactors [23], microchannel reactors [18, 24-26], fuel cells and fuel processing reactors [27-29], solar thermal collectors [31, 32], and modern agricultural irrigation systems $[33,34]$.

The geometrical structure of MCHS strongly affects the flow distribution performance $[35,36]$. The major parameters that govern this aspect are manifold layout, channel geometry, number and location of inlet and outlet ports, phase of working fluid, and secondary distributor systems. Chein and Chen [9] numerically studied the effect of various types of inlet and outlet ports location configurations, namely D-, N-, S-, U-, and V-type, on the performance of MCHSs. They found that the designs with vertical fluid supply, i.e. U- and V-type, produced better flow distribution than designs with horizontal fluid supply, i.e. I-, N-, D-, and S-type. Mohammadi et al. [36] numerically studied the impact of right triangular manifolds and microchannels on velocity distribution and pressure drop within the system. They found that the manifold structural parameters had more influence on velocity distribution compared to microchannel dimensions. Furthermore, they pointed out that due to the absence of a universal threshold value for flow uniformity within microchannels, the acceptable degree of flow nonuniformity is subjected to the application of the device. Xia et al. [40] numerically studied the effects of different inlet and outlet locations (C-, Z-, and
I-type), manifold shapes (rectangular, symmetry trapezoidal, and triangular), and microchannel geometries (conventional rectangular, offset fan-shaped reentrant cavities, and triangular reentrant cavities). They found that I-type port location and rectangular manifold produced better flow distribution. Also, they found that the addition of reentrance cavities enhanced the heat transfer performance. Lu and Wang [41] numerically studied the effect of inlet and outlet arrangement (I-, Z-, J-, L-. and $\Gamma$ ) on the performance of parallel-channel cold plate. They found that]-arrangement produced the best flow distribution and lowest pressure drop due to the absence of flow recirculation within the design. Although many studies were conducted on the location of inlet and outlet ports, this aspect is generally limited by the application and fabrication techniques. On the other hand, Hao et al. [42] numerically optimized the performance of a U-type parallel-channel heat sink. They found that the number of channels had significant effect on the flow distribution, whereas channel length and channel height had little effect. Similarly, Ma et al. [43] carried out a multi-parameter optimization for rectangular MCHSs. They found that under different parameters, the average temperature can be remarkably reduced albeit at a cost of higher pressure drops. Hajmohammadi et al. [44] studied the microfluidic effects on the heat transfer enhancement and optimal design of MCHSs by considering the slippage at the solid-fluid interface. On the other hand, some researchers investigated the effect of microchannel on the performance of MCHS. For instance, Alfaryjat et al. [43] investigated the various microchannel geometries, including hexagonal, circular, and rhombus on the thermohydraulic characteristics of MCHS. They found that hexagonal cross-section MCHS produced the highest pressure drop and heat transfer coefficient due to the smallest hydraulic diameter, whereas rhombus cross-section MCHS produced poorest thermohydraulic performance.

Many researchers have proposed innovative approaches to enhance the performance of MCHSs. For instance, Lu et al. [46] proposed the use of wavy porous fins in MCHSs to simultaneously reduce the pressure drop and thermal resistance. They found that the use of wavy porous fins resulted in better performance due to enhanced coolant mixing by the vortices created, the prolonged flow route by the increased equivalent channel length, and the forced permeation by the jet-like impingement. On the other hand, Madane and Kulkarni [18] proposed a pressure equalization approach to improve the flow uniformity significantly in microchannels. The authors highlighted that the flow maldistribution in MCHS is caused by the distance between channel and inlet and outlet ports as well as the manifold design which leads to varying velocity over the manifold region. They proposed the incorporation 
of pressure equalization slot at the inlet region of channel to improve the flow distribution by allowing the flow to mix before it gets redistributed. More recently, Ermagan and Rafee [47] proposed the use of converging microchannels with superhydrophobic walls for MCHS. They found that the use of superhydrophobic walls reduced the pressure drop and therefore, pumping power. However, it negatively impacted the thermal resistance of the device. On the other hand, the effect of converging microchannels design on the performance of MCHS was found to be highly dependent on the pumping power in which it produced positive impact at lower pumping power.

Undoubtedly, flow distribution greatly affects the performance of MCHSs, and it is very important in many applications. However, many of these studies involve complicated manifold designs or novel approaches which may not be easily incorporated due to the complexity and the lack of understanding of such approaches. Additionally, many studies have been conducted on various microchannel geometrical parameters, such as channel width, channel spacing, channel depth, and channel length. However, a simultaneous alteration of more than one parameter is relatively scarce.

The present study focuses on the effect of simple geometrical shape of manifolds and structure of microchannels on the hydrodynamic performance of MCHSs using three-dimensional CFD approach. Three different manifold layouts, namely rectangular manifold, circular manifold, and triangular manifold, and a simultaneous alteration of the microchannel width and microchannel spacing, or microchannel ratio, without exceeding the pre-specified design space constrain are examined. The hydrodynamic performance of MCHSs is evaluated using pressure drop, velocity distribution, and coefficient of flow nonuniformity.

\section{Research methodology}

\subsection{Computational model}

The model of MCHSs is shown in Fig. 1. Prior to the design of MCHSs, the geometrical dimensions of MCHSs were limited to a pre-identified maximum allowable value because the size of a heat sink is generally limited in most applications. All designs have the same number of microchannels $(n=10)$, whereas the microchannel depth was fixed at a pre-determined value. The geometrical dimensions of MCHSs are detailed in Table 1. Keeping this in mind, the geometrical design of MCHSs was carried out by considering two aspects, manifold layout and microchannel ratio. The latter involved a simultaneous alteration of

Table 1 Parameters and geometrical dimensions of MCHS

\begin{tabular}{|c|c|c|}
\hline Parameter & Designation & Value $(\mathrm{mm})$ \\
\hline Manifold width & $W_{M}$ & $<10.0$ \\
\hline Total length & $L_{T}$ & $<30.0$ \\
\hline Manifold length & $L_{M}$ & $<5.0$ \\
\hline Microchannel length & $L_{M C}$ & 20.0 \\
\hline Microchannel thickness & $T_{\mathrm{MC}}$ & 0.3 \\
\hline Port diameter & $D_{\mathrm{P}}$ & 3.0 \\
\hline Port thickness & $T_{\mathrm{P}}$ & 0.4 \\
\hline Port $x$-location & $L_{P, X}$ & $W_{M} / 2$ \\
\hline Port z-location & $L_{P, Z}$ & $L_{M} / 2$ \\
\hline Manifold length 1 (Tria) ${ }^{\mathrm{a}}$ & $L_{\mathrm{M} 1}$ & 5.0 \\
\hline Manifold length 2 (Tria) $^{a}$ & $L_{\mathrm{M} 2}$ & 1.0 \\
\hline Port $x$-location (Tria) ${ }^{a}$ & $L_{P, X, T}$ & 2.0 \\
\hline Port z-location (Tria) ${ }^{\mathrm{a}}$ & $L_{P, Z, T}$ & 2.0 \\
\hline
\end{tabular}

${ }^{\text {a}}$ These are only applicable for Tria_MCHS because of its asymmetrical manifold layout

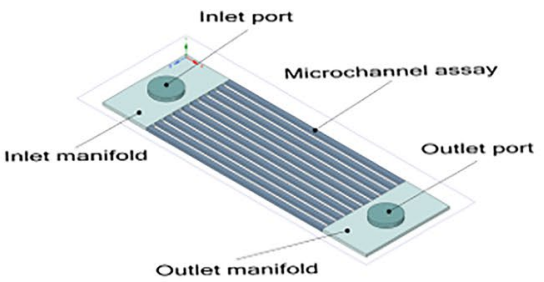

$L_{T}$
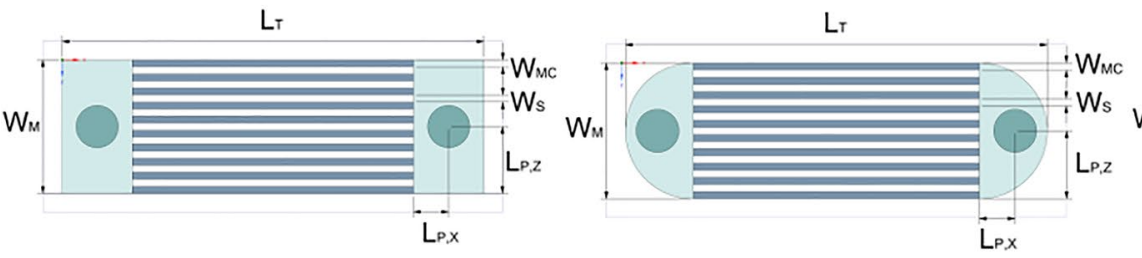

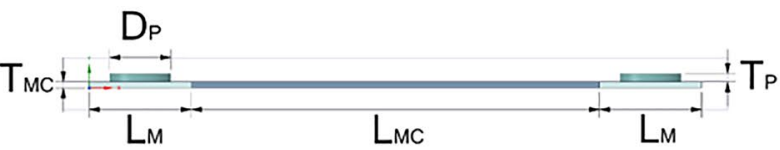

$\mathrm{L}_{\mathrm{r}}$

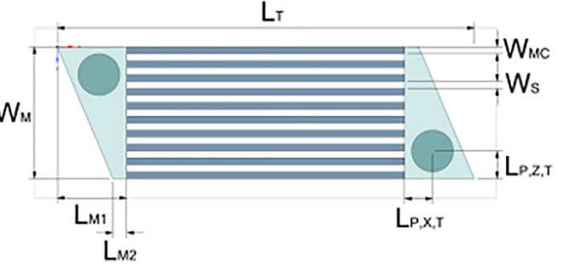

Fig. 1 Schematic of MCHSs $\left(\varnothing_{W}=1.00\right)$ 
microchannel width and microchannel spacing without exceeding the design space constrain, as listed in Table 2 where $\varnothing_{W}(1)$ is the microchannel ratio. The MCHSs established in this research were designed in such a way that they are practical and producible with the current microfabrication technologies, such as soft lithography [48, 49] and 3D printing [50].

$\varnothing_{\mathrm{W}}=\frac{W_{\mathrm{MC}}}{W_{\mathrm{S}}}$

\subsection{Mesh procedure}

The mesh procedure and specifications were detailed in Table 3. Shared topology setting was used to connect multiple bodies. This was to ensure a conform mesh between two or more bodies. Inflation was used in certain areas as such local mesh refinement provides a finer mesh quality at crucial regions without the need to produce similar mesh quality throughout the bodies. Additionally, the mesh behavior was set to hard to ensure the user input was forcefully implemented in the mesh procedure.

\subsection{Governing equations and boundary conditions}

This research focused on the hydrodynamic performance of MCHSs. Therefore, only continuity and momentum equations were involved. Although the energy aspect was not considered, the effect of density and viscosity variation was investigated by using the corresponding properties at different temperature. The entire fluid region of MCHSs was used as the computational domain. To simplify the model, several assumptions were incorporated before establishing the governing equations, including that the fluid is incompressible and has constant fluid properties as well as the fluid flow is in steady-state laminar phase. Based on the above assumptions, the governing equations for continuity and momentum used to describe the fluid flow are expressed in (2) and (3), respectively.

Continuity equation for fluid flow:

$\nabla \vec{u}=0$

Momentum equation for fluid flow:

$\rho_{f}(\vec{u} \cdot \nabla \vec{u})=-\nabla P+\nabla \cdot\left(\mu_{f} \nabla \vec{u}\right)$

The inlet boundary was located at the inlet port in which velocity-inlet was used, whereas the outlet boundary was located at the outlet port in which zero pressureoutlet was used. Water was used as working fluid and its temperature-dependant properties are listed in Table 4.

\subsection{Solution method}

The computational models were designed using SpaceClaim and meshed using Ansys Mesh. The numerical simulations were carried out using Ansys Fluent 19.1 Academic Research license. The governing equations and the boundary conditions were solved by employing SIMPLE

Table 4 Temperature-dependent properties of water

\begin{tabular}{lll}
\hline Temperature $\left({ }^{\circ} \mathrm{C}\right)$ & Density $\left(\mathrm{kg} / \mathrm{m}^{3}\right)$ & Viscosity (Pa s) \\
\hline 20 & 998.2 & 0.0010030 \\
30 & 995.7 & 0.0007978 \\
50 & 988.1 & 0.0005471 \\
70 & 977.7 & 0.0004044 \\
\hline
\end{tabular}

Table 2 Simulation modules of MCHS

\begin{tabular}{llllll}
\hline Manifold layout & Module & $W_{\mathrm{C}}$ & $W_{\mathrm{S}}$ & $W_{\mathrm{M}}$ & $\emptyset_{\mathrm{W}}$ \\
\hline Rectangular & $\mathrm{A}$ & 300 & 700 & 9300 & 0.43 \\
Circular & $\mathrm{B}$ & 400 & 600 & 9400 & 0.67 \\
Triangular & $\mathrm{C}$ & 500 & 500 & 9500 & 1.00 \\
& $\mathrm{D}$ & 600 & 400 & 9600 & 1.50 \\
& $\mathrm{E}$ & 700 & 300 & 9700 & 2.33 \\
\hline
\end{tabular}

Table 3 Mesh procedure and specifications of MCHSs

\begin{tabular}{llll}
\hline Mesh no. & Region & Method & Specifications \\
\hline 1 & Inlet port; outlet port & MultiZone & Sweep element size = user input \\
2 & Inlet port; outlet port & Inflation & Default \\
3 & Inlet port; outlet port & Face Sizing & Element size $=$ user input \\
4 & Inlet manifold 1; outlet manifold 1 & MultiZone & Sweep element size $=$ user input \\
5 & Inlet manifold 2; outlet manifold 2 & MultiZone & Sweep element size $=$ default \\
6 & Inlet manifold 2; outlet manifold 2 & Inflation & Default \\
7 & Inlet manifold 2; outlet manifold 2 & Face sizing & Element size $=$ user input \\
8 & Microchannel 1-10 & MultiZone & Sweep element size $=$ default \\
9 & Microchannel 1-10 & Edge sizing & Element size $=$ user input \\
\hline
\end{tabular}


scheme algorithm, whereas the pressure and momentum were discretized by second order and second order upwind schemes, respectively. The convergence criteria were fixed at $1 \mathrm{e}-6$.

\section{Results and discussion}

\subsection{Grid dependency test (GDT)}

Grid dependency test (GDT) was conducted to examine the mesh quality of MCHSs to ensure the reliability and accuracy of simulation results while consuming a minimum computational time. It was carried out in a similar way as reported by Mohammadi and his group [36]. The selection criterion was based on the relative error (RE) (4) of approximately $5 \%$ to that of the finest studied mesh size. GDT was firstly carried out on the microchannel region, followed by the manifold region and finally the port region, as detailed in Table 5. Rect_MCHS_C was selected for GDT and the procedure was generally opposite to that of the meshing procedure as detailed in Table 3.

Relative error, $\operatorname{RE}(\%)=\frac{x_{i}-x_{0}}{x_{0}} \times 100$

All the studied inlet flow rates were studied for the microchannel region. It was found that the face sizing element size for manifold region and the MultiZone sweep element size and face sizing element size for port region did not impose any significant effect on the simulation results. This may be attributed to the inflation layers which served as local refinement. Samples of the resulting mesh model are shown in Fig. 2.

\subsection{Model validation}

The simulation method and assumptions have been validated by comparing the results to that of the experiment work by Tretheway and Meihart [52]. Their experimental work has been used for validation by other researchers [47, $53,54]$. In this validation, a simulation with a grid size of $45 \mu \mathrm{m}, 4.5 \mu \mathrm{m}$, and $70 \mu \mathrm{m}$ were used in the edge sizing for width, depth, and length, respectively. The methodology was similar to those discussed above. The results were analyzed in terms of the velocity profile normalized with centerline velocity across the microchannel width at length of $4 \mathrm{~cm}$. The comparison of the results was plotted in Fig. 3 . The simulation results were in good agreement to that of the experiment results.

\subsection{Effect of microchannel geometrical dimension on hydrodynamic performance of microchannel heat sink}

\subsubsection{Rectangular microchannel heat sink}

Normalized velocity distribution (5) was used to determine the relative velocity difference among the microchannels, whereas coefficient of flow nonuniformity, $K_{m^{\prime}}(6)$ was used to characterize the degree of flow distribution in the microchannel assay [55]. It is a measure of the standard deviation of the flow nonuniformity. The larger the value of $K_{\mathrm{m}}$, the higher the flow nonuniformity. This dimensionless number has been used by other researchers [42].

Normalized velocity, $u_{m, i}=\frac{u_{i}}{\frac{\sum_{i}^{N} u_{i}}{N}}$

$K_{\mathrm{m}}=\sqrt{\frac{\sum_{i=1}^{N}\left(\beta_{i}-\bar{\beta}\right)^{2}}{N}}$,

where $\beta_{i}(7)$ and $\bar{\beta}(8)$ are the flow ratio for ith microchannel and average flow ratio for the total microchannels, respectively, $Q_{i}$ and $Q_{\text {total }}$ are the volume flow rate for $i$ th microchannel and total volume flow rate for the total microchannels, respectively.

$\beta_{i}=\frac{Q_{i}}{Q_{\text {total }}}$

$\bar{\beta}=\frac{\sum_{i=1}^{N} \beta_{i}}{N}$

Figure 4 shows the normalized velocity distribution among the microchannels of Rect_MCHSs. The velocity was relatively higher at the center region of microchannels
Table 5 Specifications and results of GDT

\begin{tabular}{|c|c|c|c|}
\hline No. & Specifications & Final selection & RE (\%) \\
\hline 1 & Microchannel-multizone sweep element size 7.5-110 & 50 & $\sim 5$ \\
\hline 2 & Microchannel-edge sizing element size 10-100 & 70 & $\sim 5$ \\
\hline 3 & Manifold-face sizing element size $20-200$ & 200 & 0.07 \\
\hline 4 & Port-multizone sweep element size $20-50$ & 50 & 2.48 \\
\hline 5 & Port-face sizing element size $20-200$ & 200 & 2.37 \\
\hline
\end{tabular}




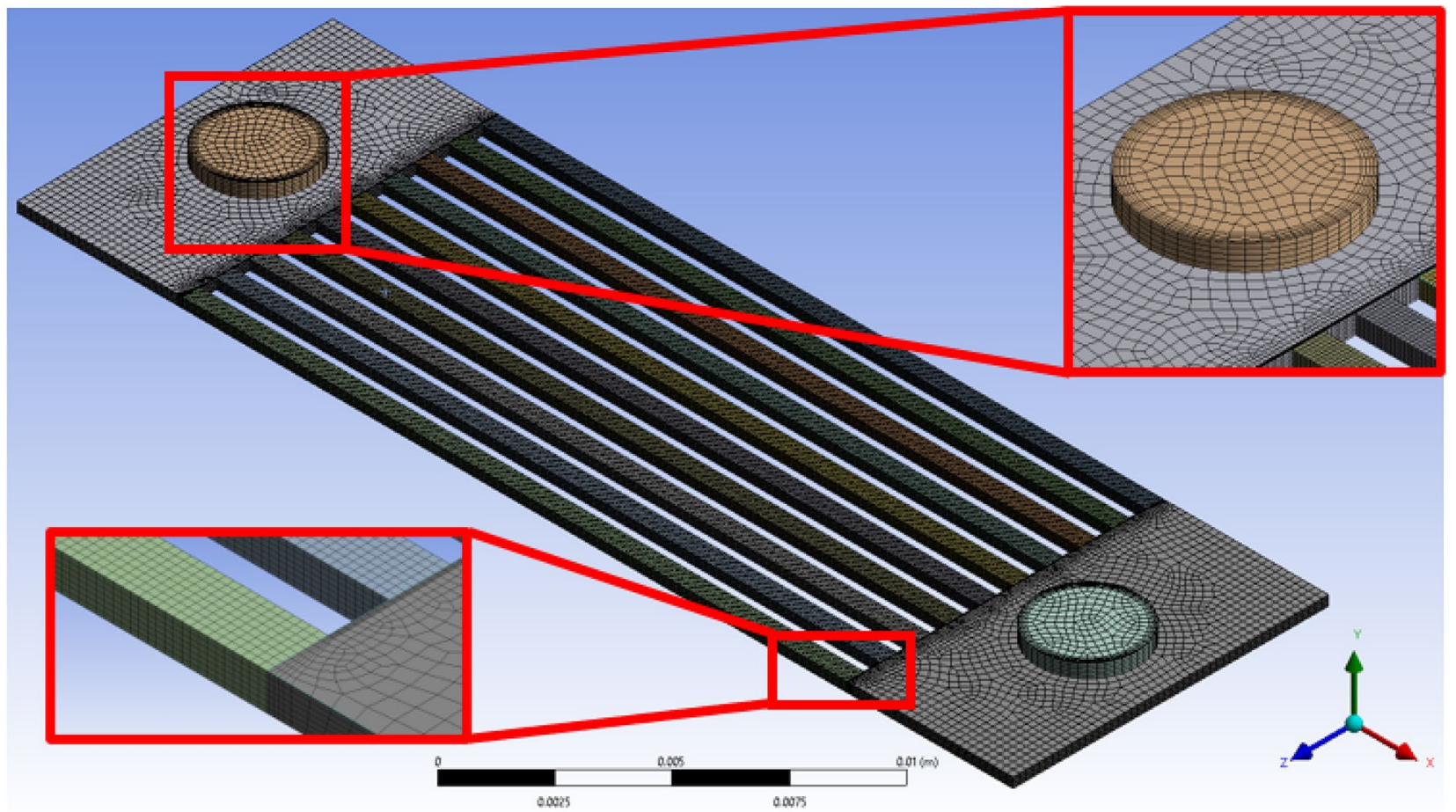

(a)

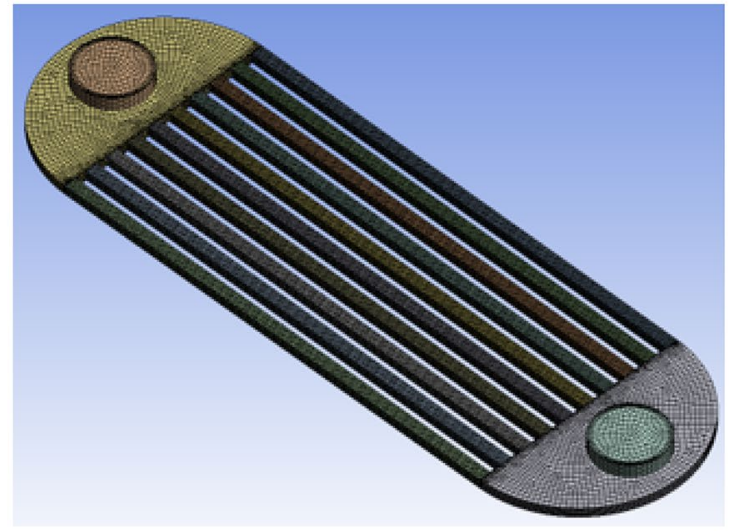

(b)

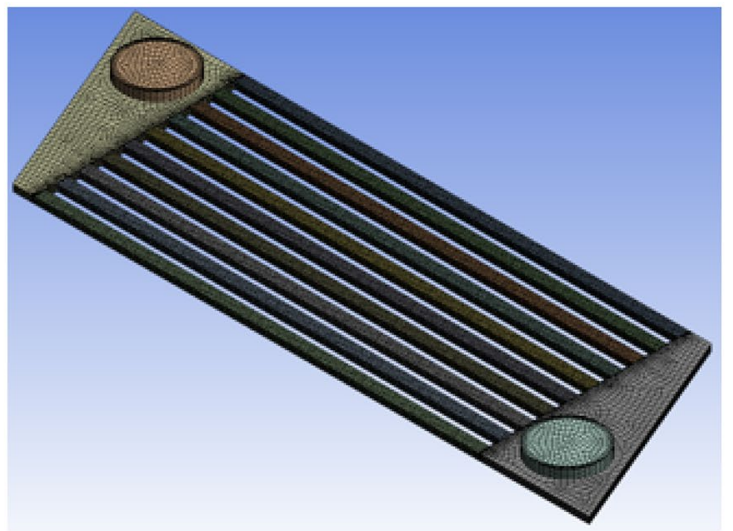

(c)

Fig. 2 Mesh model of a Rect_MCHS_C (number of elements=200,621), b Circ_MCHS_C (number of elements=197,954), and c Tria_MCHS_C (number of elements $=193,026$ )

due to the location of inlet port at the center region of the manifold, as shown in the velocity contour. In addition, the corners of the manifold have significantly lower velocity as shown by the blue contour indicating the potential formation of dead zones in these areas. However, this may not be a concern as a MCHS is usually designed in the way that the microchannel assay fully covers the heat source.

Figure 5 shows the coefficient of flow nonuniformity of Rect_MCHSs. Rect_MCHS_A resulted in the best flow distribution, as indicated by the smallest value of $K_{\mathrm{m}}$. Furthermore, the flow distribution improved at higher inlet flow rates. The better flow distribution of Rect_MCHS_A can be attributed to the large microchannel spacing in which it acts as a flow resistance to prevent the fluid to enter directly into the microchannel assay, therefore, allowing it to be dispersed into other microchannels. This effect can be observed in the velocity vector contour. This effect is not observed in small microchannel spacing of Rect_MCHS_E. Also, at higher inlet flow rates, for instance, $100 \mathrm{~mL} / \mathrm{min}$, the improvement of flow distribution is due to the stronger flow dispersion effect that is created by the microchannel spacing, as can be observed by the longer velocity vector arrow. Similarly, the effect of flow dispersion due to microchannel spacing is absent 


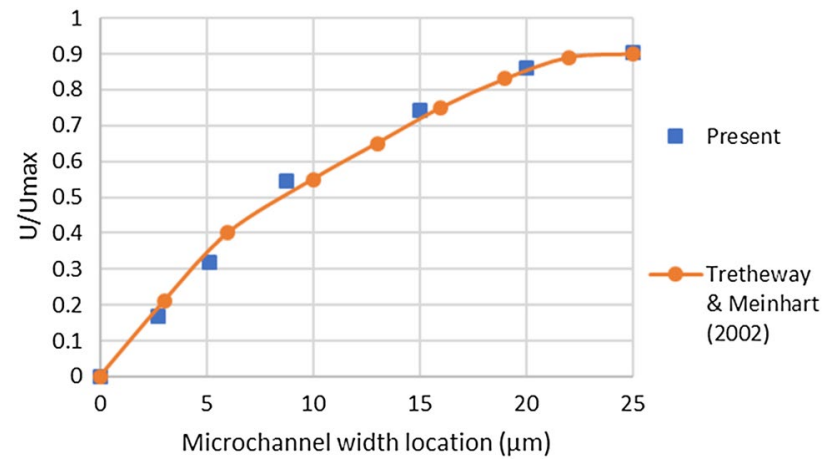

Fig. 3 Model validation for the present simulation model and experiment results using velocity profile (normalized with centerline velocity) across microchannel width (microchannel length $=4$ $\mathrm{cm})$

in Rect_MCHS_E. The results agree with other studies [26, 42]. Despite the improvement in terms of flow distribution, higher inlet flow rates resulted in higher pressure drops, as shown in Fig. 6 . The pressure drop slightly increased in the order of Rect_MCHS_E $<$ Rect_MCHS_D $<$ Rect_ MCHS_C $<$ Rect_MCHS_B $<$ Rect_MCHS A due to the higher velocity within the microchannels, and severely increased as the inlet flow rate increased.

The relationship between inlet flow rates, coefficient of flow nonuniformity, pressure drop, and microchannel ratio can be examined by plotting in a same graph, as shown in Fig. 7. The first point of each plot represents the lowest inlet flow rate, i.e. $10 \mathrm{~mL} / \mathrm{min}$, followed by $25 \mathrm{~mL} / \mathrm{min}, 50$ $\mathrm{mL} / \mathrm{min}, 75 \mathrm{~mL} / \mathrm{min}$, and $100 \mathrm{~mL} / \mathrm{min}$. Although design with smaller microchannel ratio design produced better flow distribution performance, the improvement was insignificant due to the high pressure drop penalty. This is especially true for Rect_MCHS_A in which it produced the best flow distribution among all the designs, but it did not show significant improvement even at the cost of significant higher pressure drop, as indicated by the relatively linear plot. On the other hand, Rect_MCHS_C, Rect_ MCHS_D, and Rect_MCHS_E with larger microchannel ratios showed significant improvements in terms of flow distribution at the cost of slightly higher pressure drop. It is important to point out that smaller microchannel ratio and higher inlet flow rate resulted in higher velocity in the microchannels and therefore, better flow distribution among the microchannels. Nonetheless, microchannel ratio was found to contribute significantly more to the flow distribution improvement compared to inlet flow rate as Rect_MCHS_B, Rect_MCHS_C, Rect_MCHS_D, and Rect MCHS E resulted in larger coefficient of flow nonuniformity across all the studied inlet flow rates than that of Rect MCHS A at lowest studied inlet flow rate of 10 $\mathrm{mL} / \mathrm{min}$.

\subsubsection{Circular microchannel heat sink}

Figure 8 shows the normalized velocity distribution among the microchannels of Circ_MCHSs. The velocity is relatively higher at the center region of microchannels due to the location of inlet port. On the other hand, Circ_MCHSs show better flow distribution at smaller microchannel ratios and higher inlet flow rates, as indicated by the $K_{\mathrm{m}}$ values in Fig. 9. Similarly to that of Rect_MCHSs, the improvement of flow distribution is due to the flow dispersion effect created by the microchannel spacing, which can be observed in the velocity vector contour. The flow distribution of Circ_MCHSs is similar to that of Rect_MCHSs in which the latter has a slightly better performance. The results agree with a similar study by Xia et al. [40] in which they examined three different manifold geometries, including rectangular, equilateral triangle, and trapezoidal, with inlet port and outlet port located at the center region of manifold. Their results showed that rectangular manifold produced the best flow distribution among the microchannels. The authors attributed it to the interaction of the branching of fluid into the microchannels as well as the friction offered by the walls of the manifold, in this case, the microchannel spacing.

In terms of pressure drop, it was higher for smaller microchannel ratio designs and higher inlet flow rates, as shown in Fig. 10. The relationship between inlet flow rates, coefficient of flow nonuniformity, pressure drop, and microchannel ratio is shown in Fig. 11. The effect of higher inlet flow rates, as indicated by the higher pressure drops, on the improvement of flow distribution was lower for small microchannel ratios, as indicated by the smaller gradient of the plots. Moreover, microchannel ratio contributed significantly more to the flow distribution improvement compared to inlet flow rate.

\subsubsection{Triangular microchannel heat sink}

Figure 12 shows the normalized velocity distribution among the microchannels of Tria_MCHSs. Unlike Rect_ MCHSs and Circ_MCHSs, the fluid velocity was higher in the third microchannel (Nith =3) of Tria_MCHSs due to the location of the inlet port. However, the velocity was even higher at in the microchannels located at the opposite side (Nith $=7$ and onwards). This can be attributed by two factors. First is the triangular manifold design in which the manifold converges towards the opposite end at which the inlet port is located, thereby, resulting in higher velocity. Second is the flow resistance in the converging region that is relatively lower compared to the flow resistance produced by the microchannel spacing. On the other hand, at higher inlet flow rates, the flow distribution becomes worse, as can be observed in the normalized 


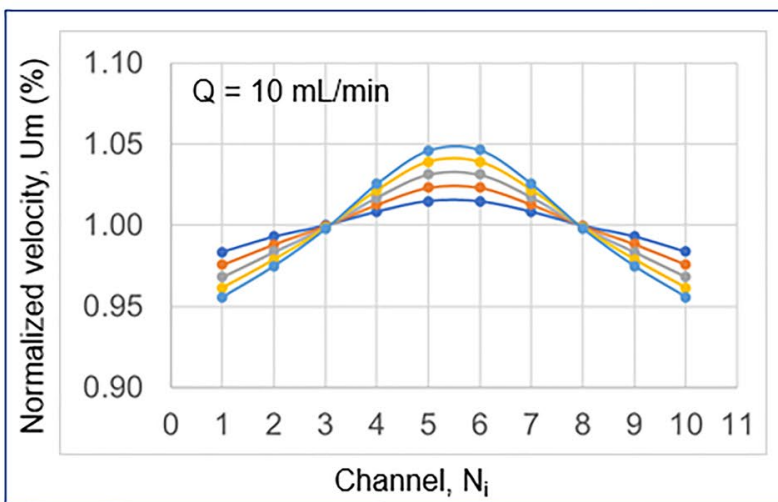

Velocity contour $(\mathrm{Q}=10 \mathrm{~mL} / \mathrm{min})$
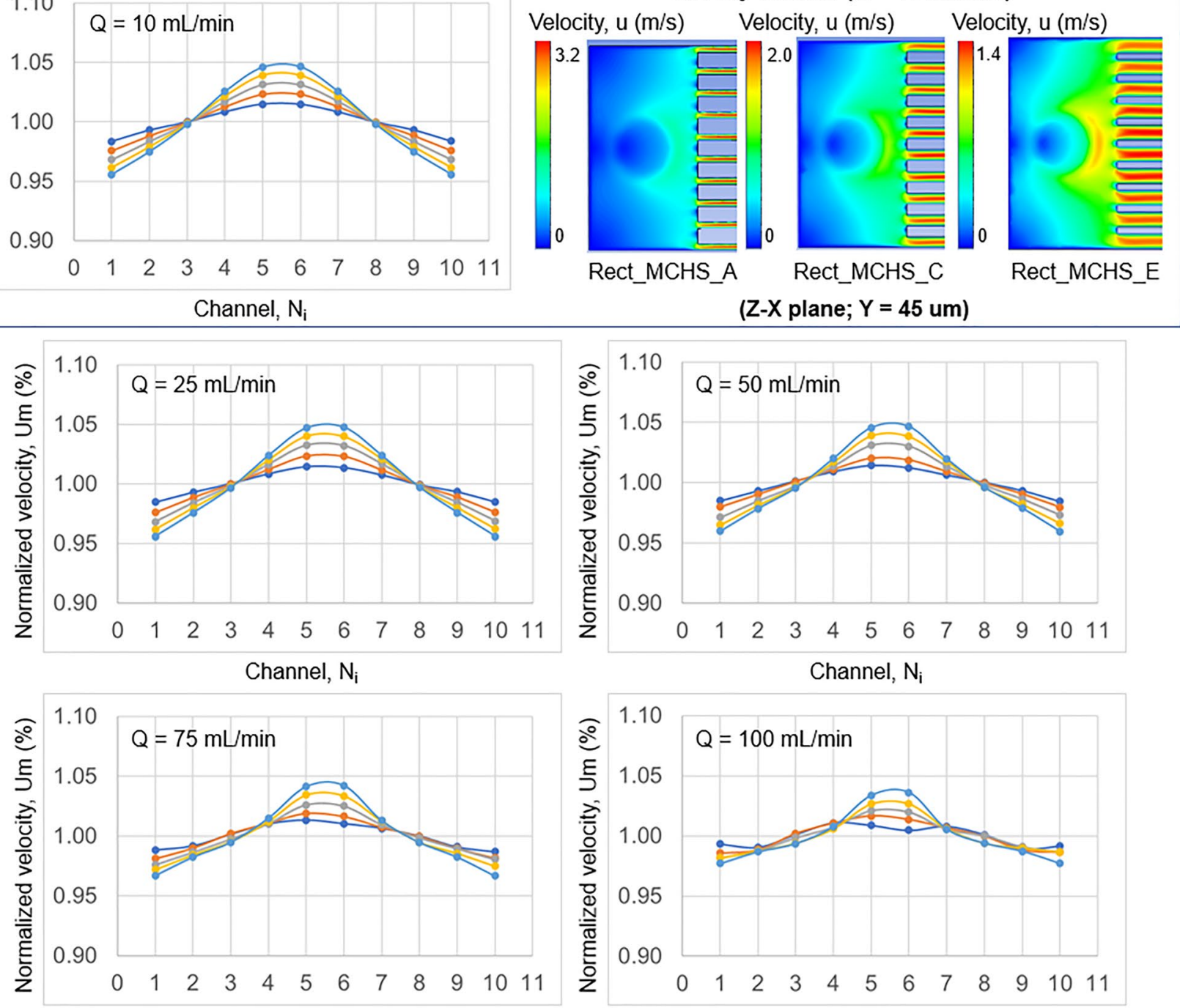

Channel, $\mathrm{N}_{\mathrm{i}}$

Channel, $\mathrm{N}_{\mathrm{i}}$

$\square$ Rect_MCHS_A $\square$ Rect_MCHS_B $\square$ Rect_MCHS_C $\square$ Rect_MCHS_D $\square$ Rect_MCHS_E

Fig. 4 Normalized velocity distribution of Rect_MCHSs

velocity distribution plots, in which the normalized velocity significantly fluctuates and severely deviates from 1.0.

Figure 13 shows the coefficient of flow nonuniformity of Tria_MCHSs. The flow distribution performance became worse at higher inlet flow rates, as indicated by the larger $K_{\mathrm{m}}$. This contradicts with the previous manifold geometries, i.e. Rect_MCHSs and Circ_MCHSs, in which higher inlet flow rates produced better flow distribution. This may be attributed to the difference in terms of the velocity distribution among the microchannels in which the velocity was higher around the third and seventh microchannels. Consequently, as the inlet flow rate increased, the velocity became much higher in these regions and therefore, resulting in more severe flow maldistribution. Thus, high inlet flow rate does not necessary produce better flow distribution. Nonetheless, the trend that designs with smaller microchannel ratios produce better flow distribution performance remains valid for Tria_MCHSs. The flow dispersion effect produced by the larger microchannel spacing resulted in a slightly stronger flow resistance of fluid into the microchannels located near the inlet port region, therefore, allowing the fluid to be dispersed into the nearby microchannels, as indicated by the velocity vector contour.

In terms of pressure drop, smaller microchannel ratios and higher inlet flow rates result in higher pressure drops, as shown in Fig. 14. The relationship between inlet flow rates, coefficient of flow nonuniformity, pressure drop, 
Fig. 5 Coefficient of flow nonuniformity of Rect_MCHSs

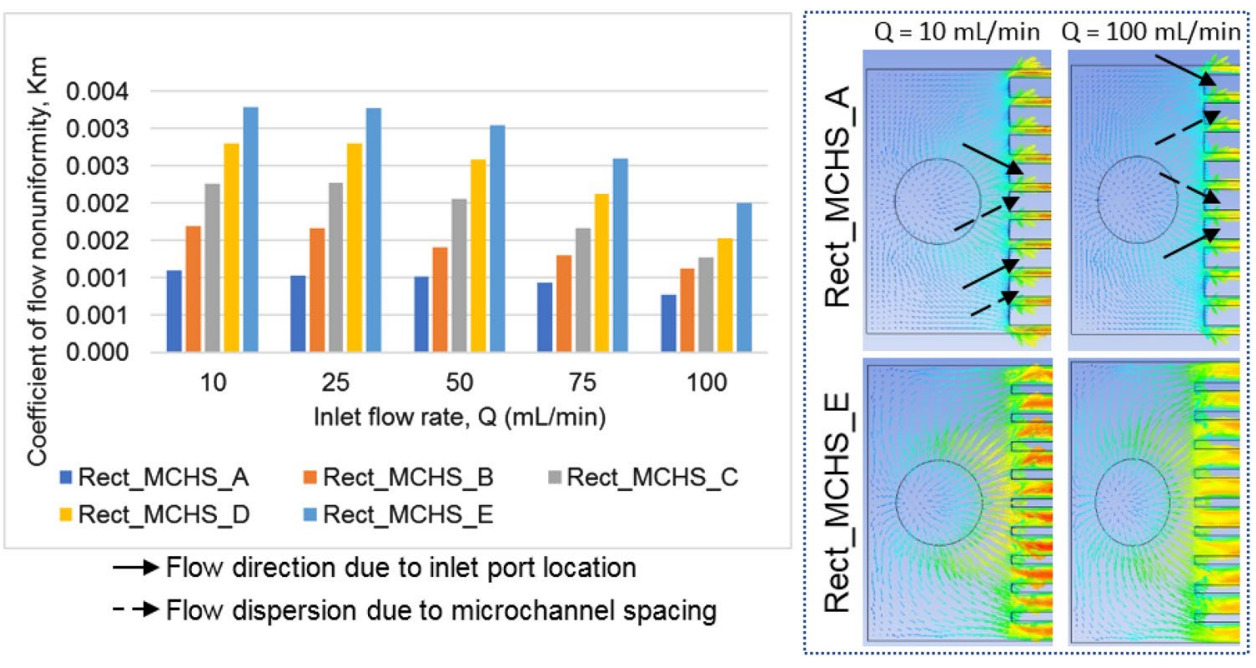

Fig. 6 Pressure drop of Rect MCHSs

Fig. 7 Relationship between coefficient of flow nonuniformity and pressure drop of Rect_MCHSs
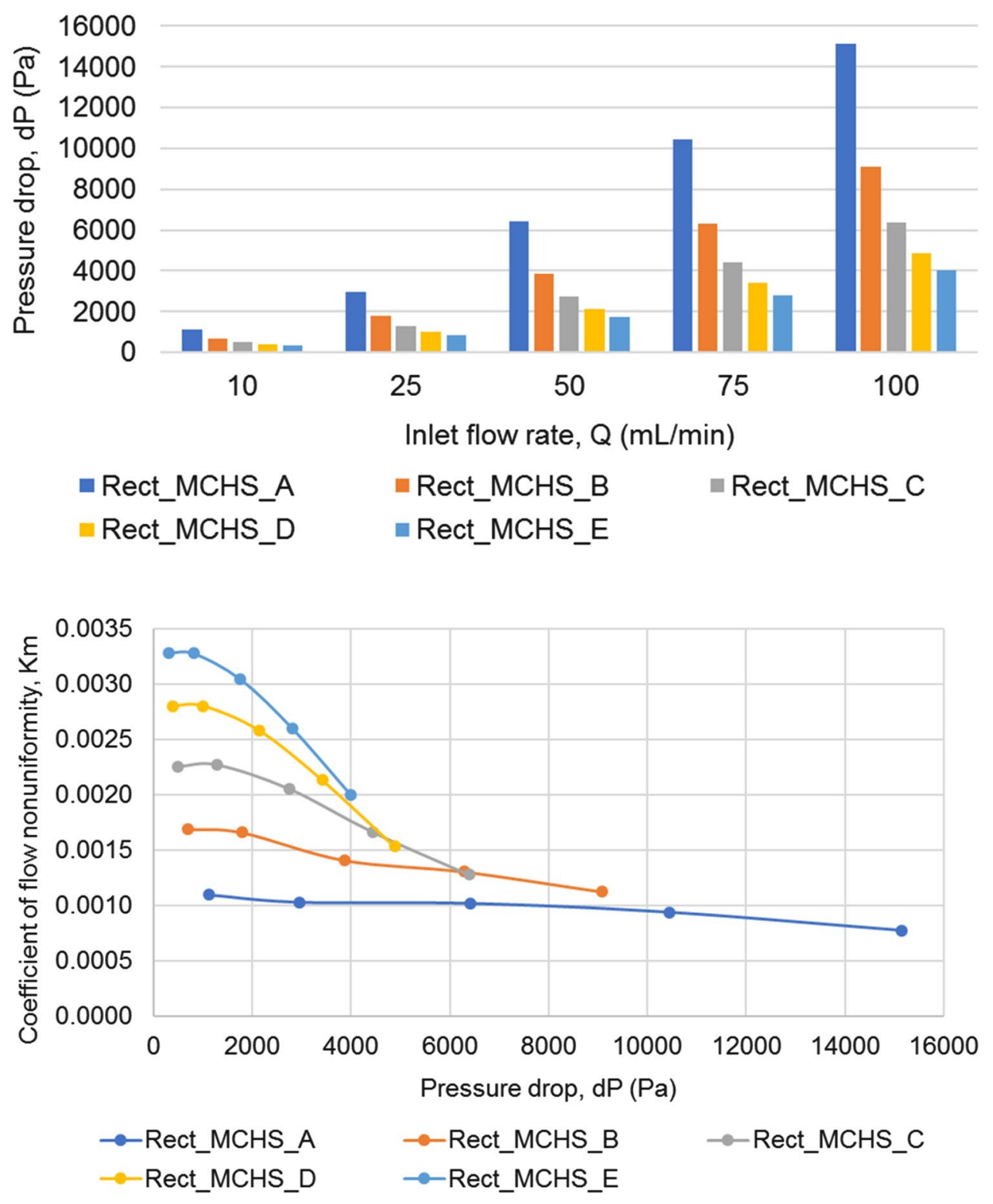

SN Applied Sciences 

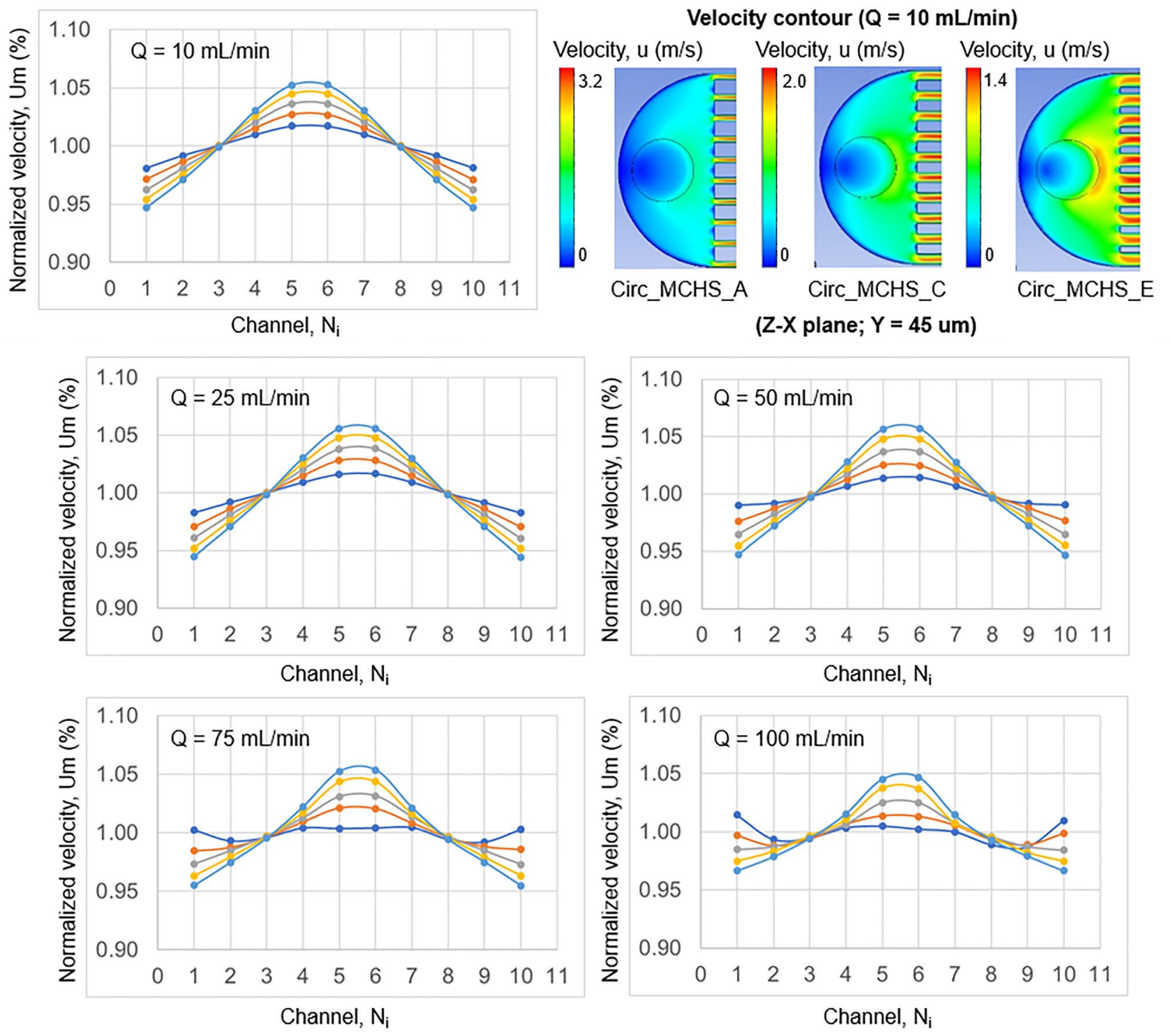

$\square$ Circ_MCHS_A $\square$ Circ_MCHS_B $\square$ Circ_MCHS_C $\square$ Circ_MCHS_D $\square$ Circ_MCHS_E

Fig. 8 Normalized velocity distribution of Circ_MCHSs

and microchannel ratio is shown in Fig. 15. Overall, Tria MCHSs produced poorer flow distribution performance. This can be attributed to the asymmetrical design of triangular manifold. As the inlet flow rate increased, the flow maldistribution was amplified. The results are consistent with other similar studies available in the literature. For instance, Pan and his group [37] showed that symmetrical manifold could achieve better velocity distribution among microchannels as compared to asymmetrical manifold. However, unlike Rect_MCHSs and Circ_MCHSs, Tria_MCHSs produced better flow distribution performance at lower inlet flow rates, even outperformed those of Rect_MCHSs and Circ_MCHSs at the lowest studied inlet flow rates. Although a higher inlet flow rate is desirable to heat transfer applications, the capability to produce a good flow distribution at a lower inlet flow rate is an advantage of triangular manifold geometry as it suffers from smaller pressure drops and therefore, lower pumping requirement.

\subsection{Effect of temperature on the hydrodynamic performance of microchannel heat sink}

In heat transfer applications, temperature variation occurs within MCHS. Therefore, this section aims to investigate the effect of temperature on the hydrodynamic performance of 
Fig. 9 Coefficient of flow nonuniformity of Circ_MCHSs

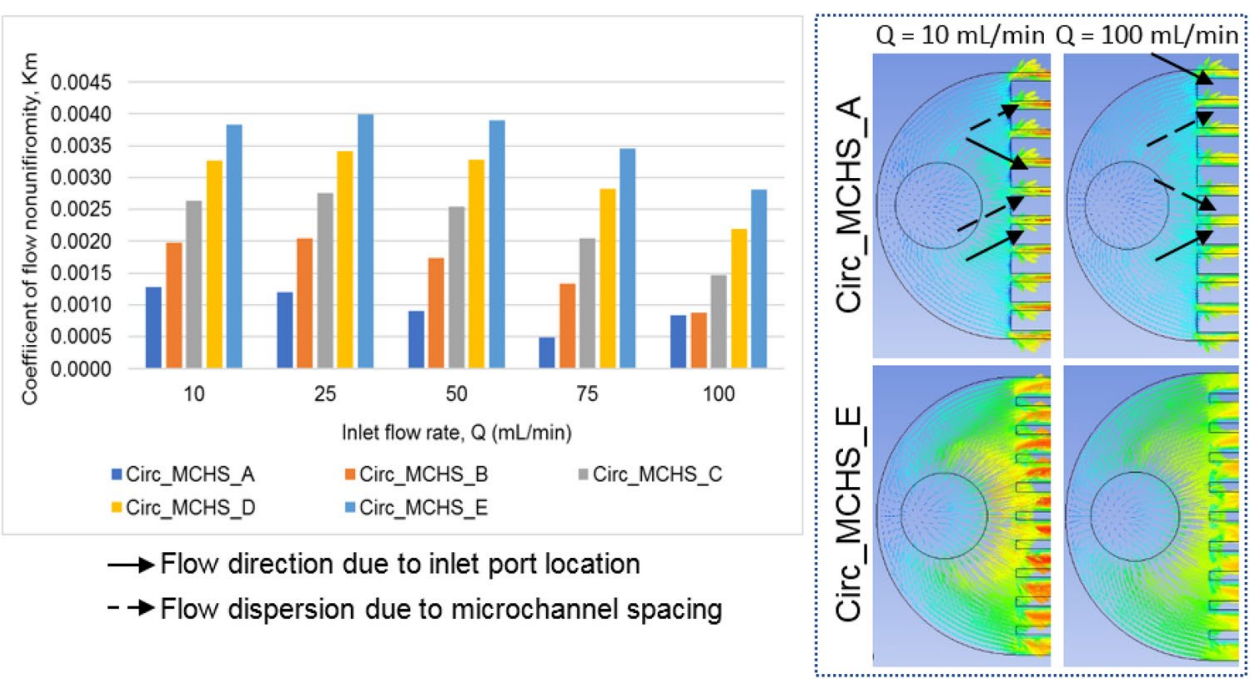

Fig. 10 Pressure drop of Circ_MCHSs

Fig. 11 Relationship between coefficient of flow nonuniformity and pressure drop of Circ_MCHSs
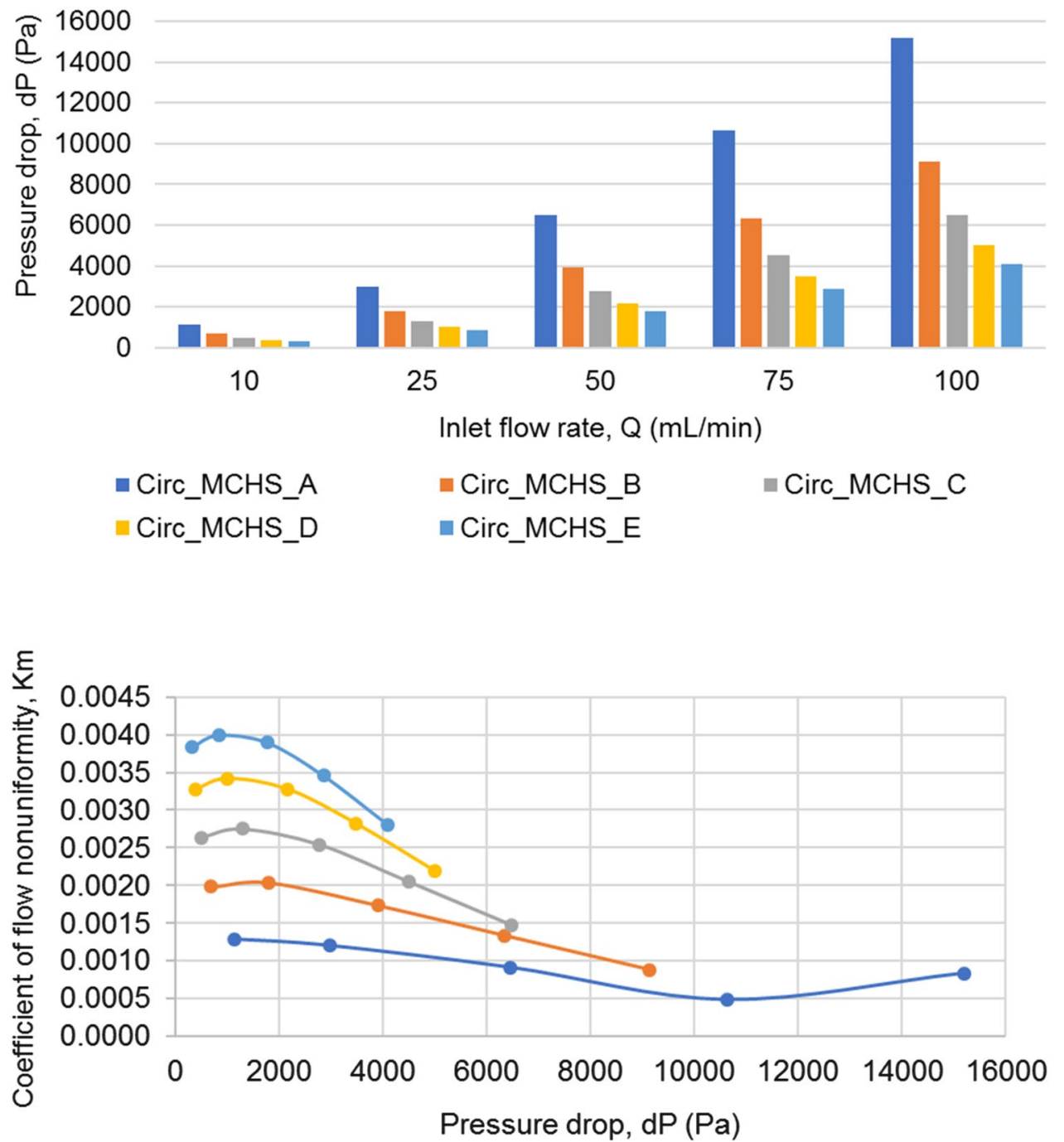

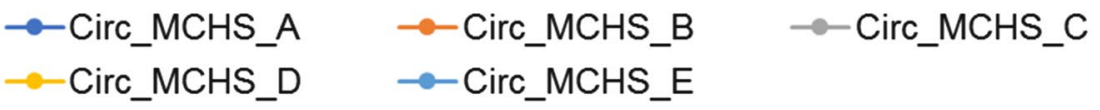

SN Applied Sciences 

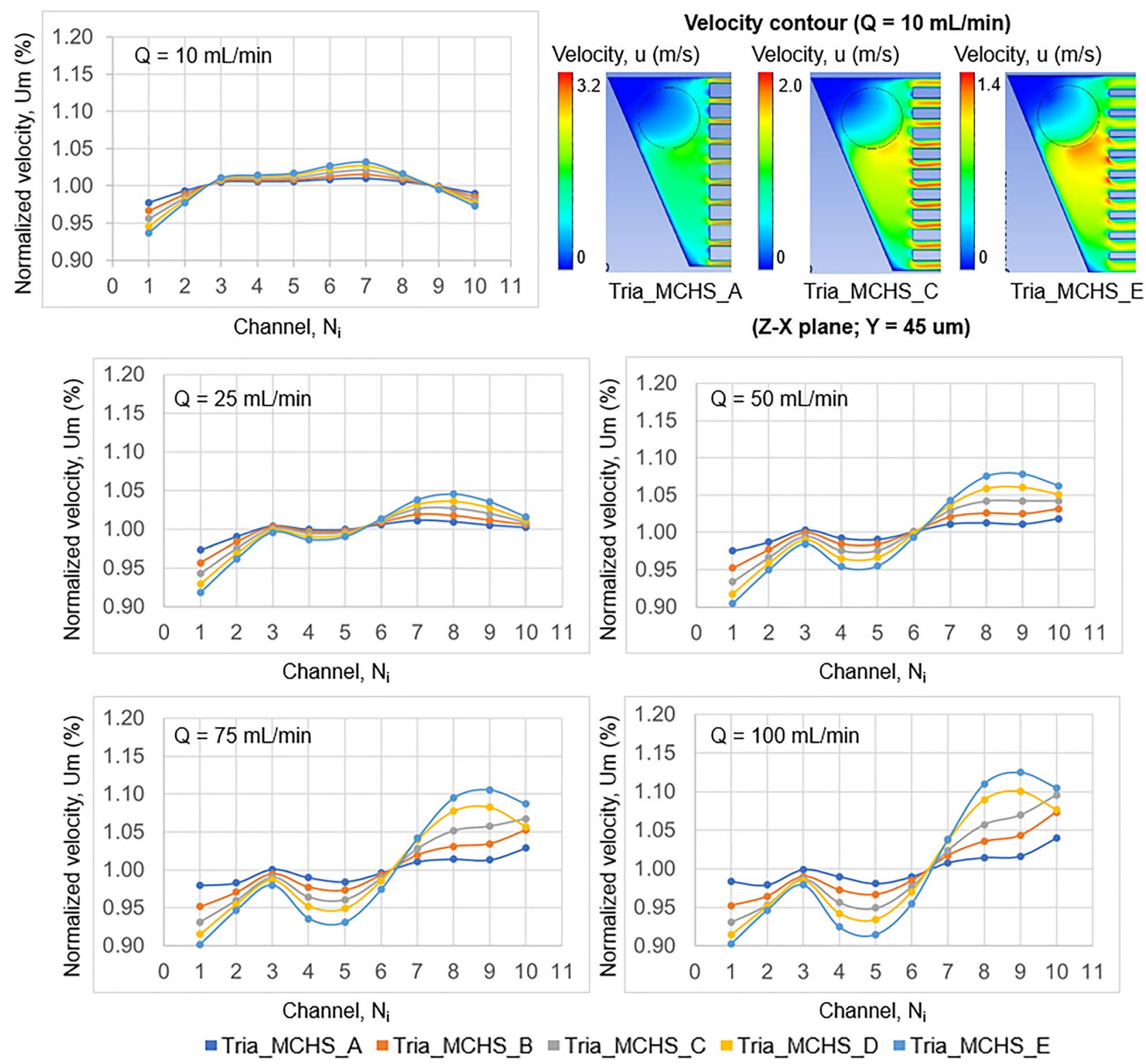

Fig. 12 Normalized velocity distribution of Tria_MCHSs

MCHS. The hydrodynamic performance of MCHS was further investigated at $30^{\circ} \mathrm{C}, 50^{\circ} \mathrm{C}$, and $70^{\circ} \mathrm{C}$ and compared to the previous results which were investigated at $20^{\circ} \mathrm{C}$. Rect_MCHS_A was selected as it produced the best overall hydrodynamic performance, whereas Rect_MCHS_E was selected as an additional comparison as it produced the worst flow distribution performance among the rectangular manifold. Further more, two flow rates of $10 \mathrm{~mL} / \mathrm{min}$ and $100 \mathrm{~mL} / \mathrm{min}$ were selected to provide a more comprehensive comparison. Figure 16 shows the results of pressure drop of MCHSs at different temperature. Pressure drop was lower at higher temperature settings. This was expected because of the lower viscosity of water at higher temperature. Figure 17 shows the results of coefficient of flow nonuniformity of MCHSs at different temperature. It should be noted that a lower viscosity at higher temperature results in a faster flow velocity. However, the $K_{\mathrm{m}}$ values showed negligible changes across different temperature, especially when compared to Rect_MCHS_E. This was due to the insignificant variation of velocity across the studied temperature range compared to the higher velocity resulted by higher inlet flow rates and the microchannel ratio, as shown in the normalized velocity distribution graphs provided in Fig. 18. Furthermore, in most applications, the heated region is located downstream of MCHS where the change in viscosity and flow velocity should not be a concern to the flow distribution performance. This 
Fig. 13 Coefficient of flow nonuniformity of Tria_MCHSs

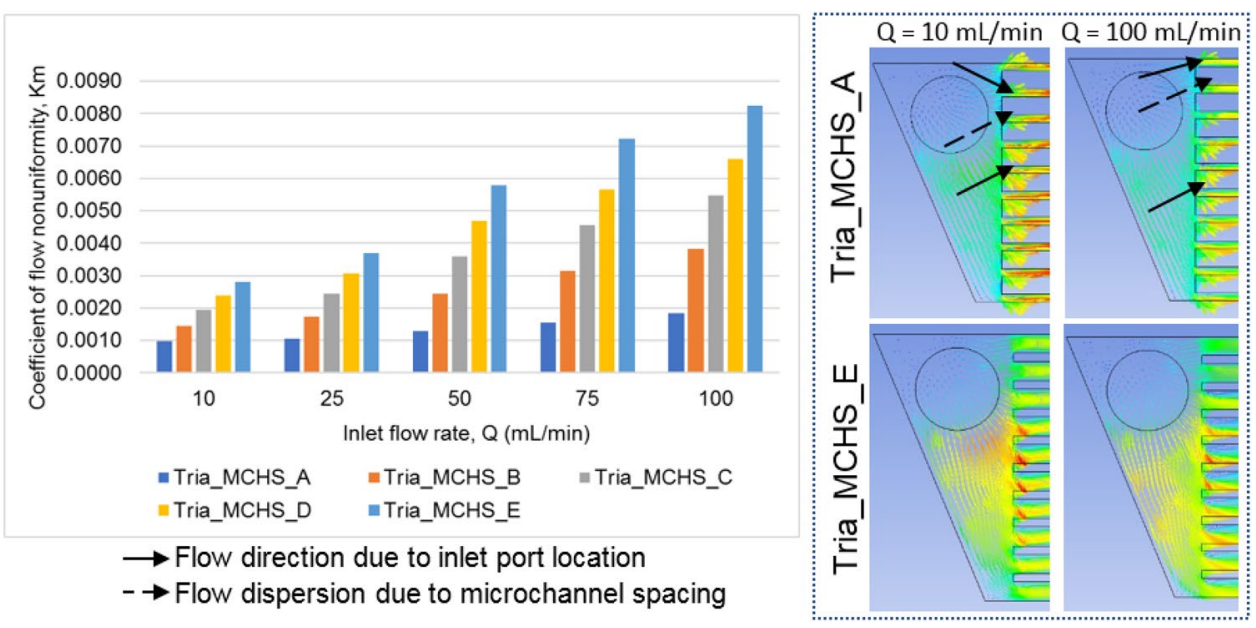

Fig. 14 Pressure drop of Tria_MCHSs

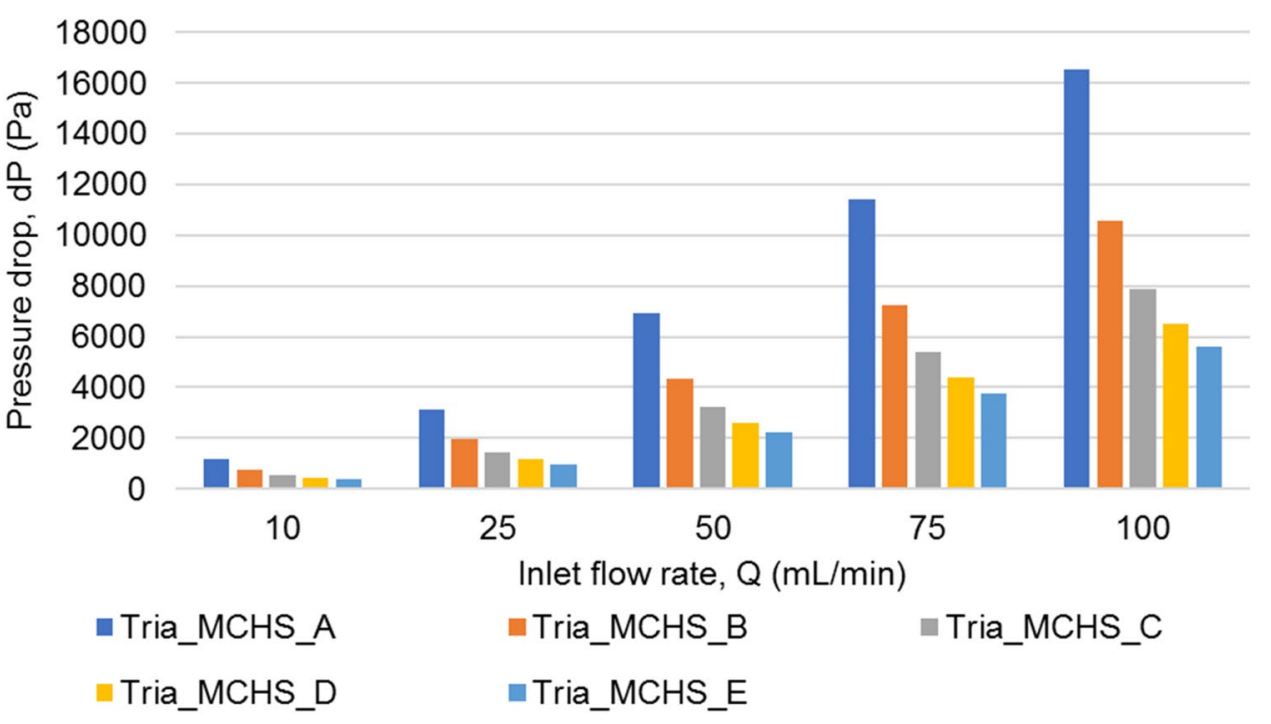

finding suggests that relevant studies could be conducted by only investigate the fluid region of MCHS to optimize the flow distribution performance rather than the entire MCHS model in which the solid region is included. This could significantly reduce the computational time required for simulations. As an example, in this study, the fluid region of a design was made of approximately 200,000 elements. The inclusion of solid region of MCHS would increase the total number of elements to more than one million. This would exponentially increase the computational time, especially if a study involves a transient analysis.

\section{Conclusion}

The effect of manifold layouts and microchannel geometry on the hydrodynamic performance of MCHSs have been thoroughly investigated using 3D CFD approach. Rectangular, circular, and triangular manifolds were selected due to their simplicity in terms of geometrical parameters and design aspects which may be favorable in many applications. Furthermore, microchannel geometry was analyzed in terms of microchannel ratio in which microchannel width and microchannel spacing were simultaneously altered to maintain a pre-specified maximum width as this aspect is generally subjected to space constrain in most applications. Lastly, the effect of temperature on the hydrodynamic performance of MCHS was investigated at a broad range of temperature using the corresponding water properties. The following conclusions can be made based on the simulation results:

1 Inlet flow rate and microchannel ratio affected the hydrodynamic performance of MCHSs. For Rect MCHSs and Circ_MCHSs, higher inlet flow rates and smaller microchannel ratios produced better flow distribution performance in which the latter aspect has higher positive impact on the hydrodynamic per- 

coefficient of flow nonuniformity and pressure drop of Tria_MCHSs
Fig. 15 Relationship between

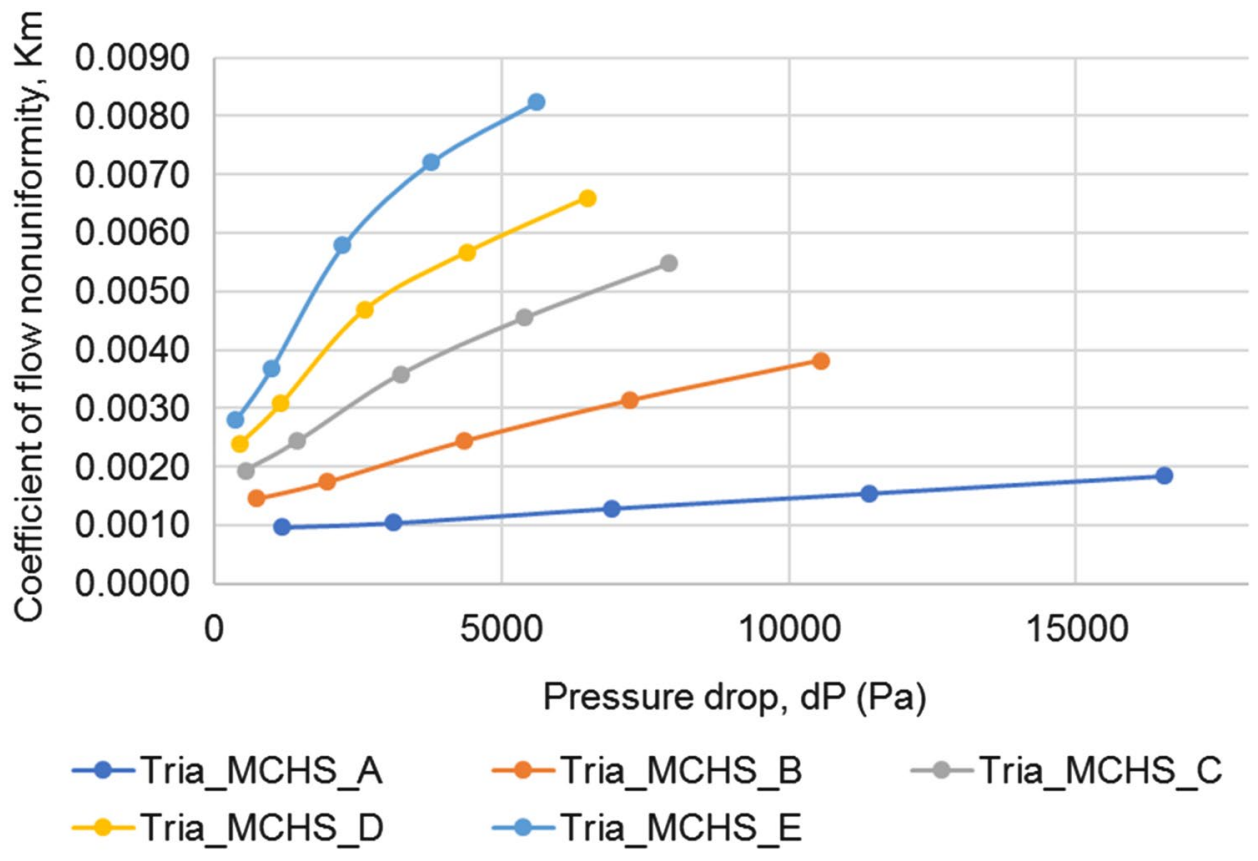

Fig. 16 Pressure drop of MCHSs at different temperature

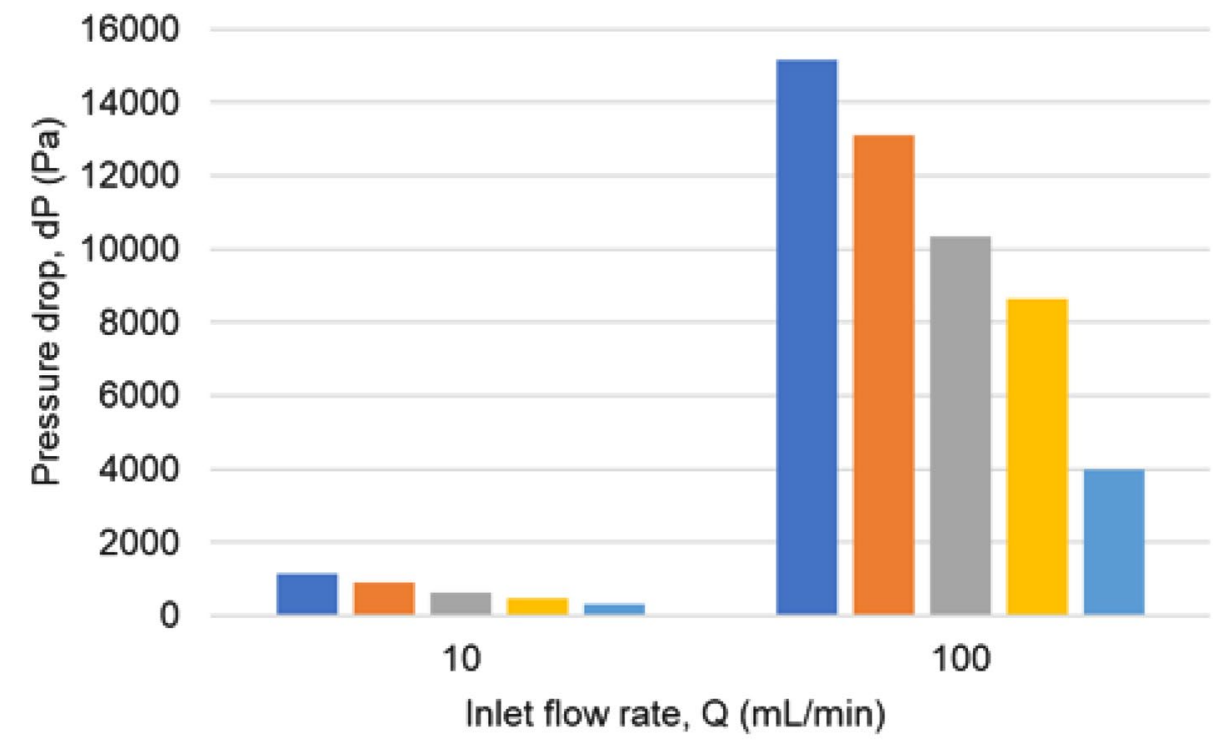

formance of MCHSs. This was due to the larger microchannel spacing in smaller microchannel ratio designs in which it served as a flow resistance barrier to create a flow dispersion effect to distribute the fluid into other microchannels. This effect was further amplified at higher inlet flow rates.

2 In terms of flow distribution performance, Tria_MCHSs resulted in opposite performance to that of Rect
MCHSs and Circ_MCHSs in which they produced severe flow maldistribution at higher inlet flow rates. This was due to the asymmetrical design in which the inlet port was located at the side of the manifold. However, Tria_MCHSs produced the lowest coefficient flow nonuniformity at the lowest studied inlet flow rate among the studied manifold types. This indicated its 
Fig. 17 Coefficient of flow nonuniformity of MCHSs at different temperature

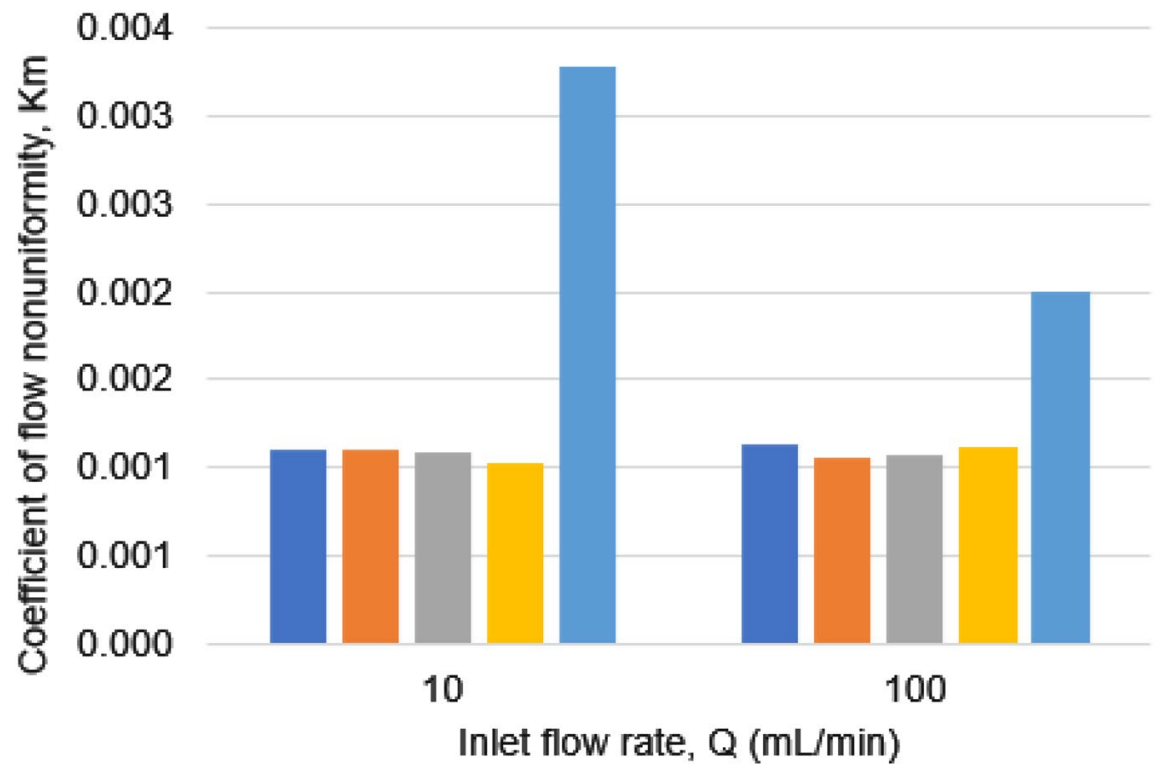

Rect_MCHS_A $@ \mathrm{~T}=20^{\circ} \mathrm{C}$
Rect_MCHS_A $@ \mathrm{~T}=30^{\circ} \mathrm{C}$
Rect_MCHS_E $@ \mathrm{~T}=20^{\circ} \mathrm{C}$

n Rect_MCHS_A @ T $=30^{\circ} \mathrm{C}$ - Rect_MCHS_A@ T $=70^{\circ} \mathrm{C}$

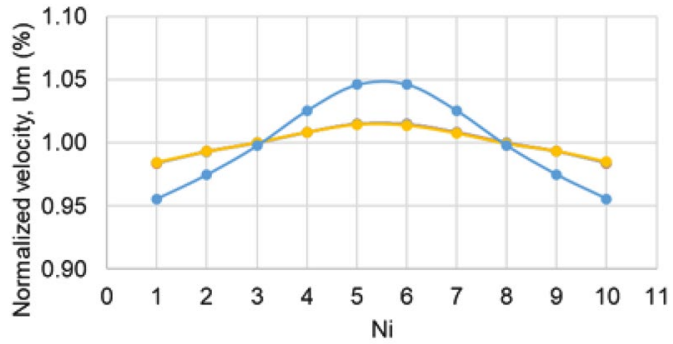

(a)

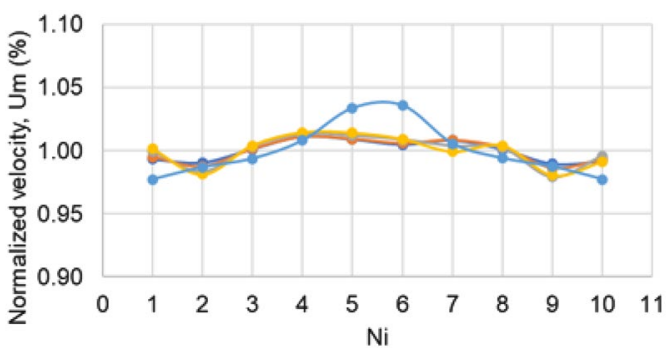

(b)

-Rect_MCHS_A@ T $=20^{\circ} \mathrm{C}$ - Rect_MCHS_A@ $@=30^{\circ} \mathrm{C}$ aRect_MCHS_E@ T $=20^{\circ} \mathrm{C}$

Fig. 18 Normalized velocity distribution of MCHSs at different temperature at a $Q=10 \mathrm{~mL} / \mathrm{min}$ and $\mathbf{b} Q=100 \mathrm{~mL} / \mathrm{min}$
= Rect_MCHS_A @ T $=30^{\circ} \mathrm{C}$ Rect_MCHS_A@T $970^{\circ} \mathrm{C}$

feasibility at lower inlet flow rate for non-heat transfer applications.

3 Variation of temperature showed negligible effect on the hydrodynamic performance of MCHS. This was due to the insignificant variation of velocity resulted by the change in viscosity of water at different temperature. Therefore, studies that focus on the flow distribution performance can be conducted by only consider the fluid region. This could significantly reduce the computational time.

The overall hydrodynamic performance was found to be in the order of Rect_MCHSs > Circ_MCHSs > Tria_MCHSs. Considering the hydrodynamic performance, simplicity, and fabrication perspective, Rect_MCHS with smaller microchannel ratio design was the best choice.

Acknowledgements This work was supported by The Murata Science Foundation [Grant no. 015ME0-031].

\section{Compliance with ethical standards}

Conflict of interest The authors declare that they have no conflict of interest.

\section{References}

1. Ghani IA, Sidik NAC, Kamaruzaman N (2017) Hydrothermal performance of microchannel heat sink: the effect of channel design. Int J Heat Mass Transf 107:21-44 
2. Shen H, Jin X, Zhang F, Xie G, Sunden B, Yan H (2017) Computational optimization of counter-flow double-layered microchannel heat sinks subjected to thermal resistance and pumping power. Appl Therm Eng 121:180-189

3. Yeh LT (1995) Review of heat transfer technologies in electronic equipment. J Electron Pack 117

4. Yang B, Wang P, Bar-Cohen A (2007) Mini-contact enhanced thermoelectric cooling of hot spots in high power devices. IEEE Trans Compon Packag Technol 30:432-438

5. Li HY, Chiang $\mathrm{MH}$, Lee $\mathrm{Cl}$, Yang WJ (2010) Thermal performance of plate-fin vapor chamber heat sinks. Int Commun Heat Mass Transfer 37:731-738

6. U.S. Air force avionics integrity program notes, 1989.

7. Ahmed HE, Salman BH, Kherbeet AS, Ahmed MI (2018) Optimization of thermal design of heat sinks: a review. Int J Heat Mass Transf 118:129-153

8. Tuckerman DB, Pease RFW (1987) High-performance heat sinking for vlsi. IEEE Electron Device Lett 3:126-129

9. Chein RY, Chen JH (2009) Numerical study of the inlet/outlet arrangement effect on microchannel heat sink performance. Int J Therm Sci 48:1627-1638

10. Lee HY, Jeong YW, Shin JH, Baek JH, Kang MK, Chun KJ (2004) Package embedded heat exchanger for stacked multi-chip module. Sens Actuators, A 114:204-211

11. Hasan MI (2011) Numerical investigation of counter flow microchannel heat exchanger with mepcm suspension. Appl Therm Eng 31:1068-1075

12. Srihari N, Prabhakara Rao B, Sunden B, Das SK (2005) Transient response of plate heat exchangers considering effect of flow maldistribution. Int J Heat Mass Transf 48:3231-3243

13. Ali Abdallah YM, Abo-Zahhad Essam M, Elkady MF, Shinichi O, El-Shazly AH, Ali R (2020) Temperature uniformity enhancement of densely packed high concentrator photovoltaic module using four quadrants microchannel heat sink. Sol Energy 202:446-464

14. Reddy KS, Lokeswaran S, Pulkit A, Mallick Tapas K (2014) Numerical investigation of micro-channel based active module cooling for solar CPV system. Energy Procedia 54:400-416

15. Karwa R, Karwa N, Misra R, Agarwal P (2007) Effect of flow maldistribution on thermal performance of a solar air heater array with subcollectors in parallel. Energy 32:1260-1270

16. Madane K, Kulkarni AA (2018) Pressure equalization approach for flow uniformity in microreactor with parallel channels. Chem Eng Sci 176:96-106

17. Siddiqui OK, Zubair SM (2017) Efficient energy utilization through proper design of microchannel heat exchanger manifolds: a comprehensive review. Renew Sustain Energy Rev 74:969-1002

18. Griffini G, Gavriilidis A (2007) Effect of microchannel plate design on fluid flow uniformity at low flow rates. Chem Eng Technol 30:395-406

19. Liu H, Li P, Lew JV (2010) Cfd study on flow distribution uniformity in fuel distributors having multiple structural bifurcations of flow channels. Int J Hydrogen Energy 35:9186-9198

20. Liu H, Li P, Wang K (2015) The flow downstream of a bifurcation of a flow channel for uniform flow distribution via cascade flow channel bifurcations. Appl Therm Eng 81:114-127

21. Ramos-Alvarado B, Li P, Liu H, Hernandez-Guerrero A (2011) Cfd study of liquid-cooled heat sinks with microchannel flow field configurations for electronics, fuel cells, and concentrated solar cells. Appl Therm Eng 31:2494-2507

22. Mokhtari S, Kudriavtsev VV, Danna M (1997) Flow uniformity and pressure variation in multi-outlet flow distribution pipes. Adv Anal Exp Comput Technol Fluids Struct Trans Nat Hazards 355:113-121

\section{SN Applied Sciences}

23. Commenge JM, Falk L, Corriou JP, Matlosz M (2002) Optimal design for flow uniformity in microchannel reactors. AlChe J 48:345-358

24. Doku GN, Verboom W, Reinhoudt DN, van den Berg A (2005) On-microchip multiphase chemistry-a review of microreactor design principles and reagent contacting modes. Tetrahedron 61:2733-2742

25. Hessel V, Lowe H (2003) Microchannel engineering components, plant concepts, user acceptance: part ii. Chem Eng Technol 26:531-544

26. Holladay JD, Wang Y, and Jones E (2004) Review of developments in portable hydrogen production using microreactor technology. Chem Rev 104.

27. Danilov VA, Tade MO (2009) A cfd-based model of a planar sofc for anode flow field design. Int J Hydrogen Energy 34:8998-9006

28. Rahimi-Esbo M, Ranjbar AA, Ramiar A, Alizadeh E, Aghaee M (2016) Improving pem fuel cell performance and effective water removal by using a novel gas flow field. Int J Hydrogen Energy 41:3023-3037

29. Shyam Prasad KB, Suresh PV, Jayanti S (2009) A hydrodynamic network model for interdigitated flow fields. Int J Hydrogen Energy 34:8289-8301

30. Wang X-D et al (2010) An inverse geometry design problem for optimization of single serpentine flow field of pem fuel cell. Int J Hydrogen Energy 35:4247-4257

31. Facão J (2015) Optimization of flow distribution in flat plate solar thermal collectors with riser and header arrangements. Sol Energy 120:104-112

32. Weitbrecht V, Lehmann D, Richter A (2002) Flow distribution in solar collectors with laminar flow conditions. Sol Energy 73:433-441

33. Ascough GW, Kiker GA (2002) The effect of irrigation uniformity on irrigation water requirements. Water SA 28:235-242

34. López-Mata E, Tarjuelo JM, de Juan JA, Ballesteros R, Domínguez A (2010) Effect of irrigation uniformity on the profitability of crops. Agric Water Manag 98:190-198

35. Pan MQ, Tang Y, Zhou W (2007) Flow distribution among microchannels with asymmetrical manifolds. Presented at the IEEE International Conference on Control and Automation, Guangzhou, China, 2007

36. Mohammadi M, Jovanovic GN, Sharp KV (2013) Numerical study of flow uniformity and pressure characteristics within a microchannel array with triangular manifolds. Comput Chem Eng 52:134-144

37. Pan MQ, Zeng DH, Tang Y, Chen DQ (2009) Cfd-based study of velocity distribution among multiple parallel microchannels. J Comput 4:1133-1138

38. Pan M, Tang Y, Pan L, Lu L (2008) Optimal design of complex manifold geometries for uniform flow distribution between microchannels. Chem Eng J 137:339-346

39. Bejan A, Errara MR (1997) Deterministic tree networks for fluid flow: geometry for minimal flow resistance between a volume and one point. Fractals 5:685-695

40. Xia GD, Jiang J, Wang J, Zhai YL, Ma DD (2015) Effects of different geometric structures on fluid flow and heat transfer performance in microchannel heat sinks. Int J Heat Mass Transf 80:439-447

41. Lu MC, Wang CC (2006) Effect of inlet location on the performance of parallel-channel cold plate. IEEE Trans Compon Packag Technol 29:30-38

42. Hao XH, Wu ZX, Chen XF, Xie GN (2014) Numerical analysis and optimization on flow distribution and heat transfer of a u-type parallel channel heat sink. Adv Mech Eng 7:1-11

43. Alfaryjat AA, Mohammed HA, Mariah AN, Ariffin MKA, Najafabadi MI (2014) Influence of geometrical parameters of hexagonal, circular, and rhombus microchannel heat sinks on the 
thermohydraulic characteristics. Int Commun Heat Mass Transfer 52:121-131

44. Ma DD, Xia GD, Jia YT, Li YF, Wang J (2017) Multi-parameter optimization for micro-channel heat sink under different constraint conditions. Appl Therm Eng 120:247-256

45. Hajmohammadi MR, Alipour P, Parsa H (2018) Microfluidic effects on the heat transfer enhancement and optimal design of microchannels heat sinks. Int J Heat Mass Transf 126:808-815

46. Lu G, Zhao J, Lin L, Wang X-D, Yan W-M (2017) A new scheme for reducing pressure drop and thermal resistance simultaneously in microchannel heat sinks with wavy porous fins. Int J Heat Mass Transf 111:1071-1078

47. Ermagan H, Rafee R (2018) Effect of pumping power on the thermal design of converging microchannels with superhydrophobic walls. Int J Therm Sci 132:104-116

48. Kim P, Kwon KW, Park MC, Lee HL, Kim SM, Suh KY (2008) Soft lithography for microfluidics: a review. Biochip J 2:1-11

49. Qin D, Xia Y, Whitesides GM (2010) Soft lithography for microand nanoscale patterning. Nat Protoc 5:491-502

50. Macdonald NP, Cabot JM, Smejkal P, Guijt RM, Paull B, Breadmore MC (2017) Comparing microfluidic platform of threedimensional (3d) printing platforms. Anal Chem 89:3858-3866
51. Qu WL, Mudawar I (2002) Experimental and numerical study of pressure drop and heat transfer in a single phase microchannel heat sink. Int J Heat Mass Transf 45:2549-2565

52. Tretheway DC, Meinhart CD (2002) Apparent fluid slip at hydrophobic microchannel walls. Phys Fluids 14(3):9-12

53. Roy P, Anand NK, Banerjee D (2013) Liquid slip and heat transfer in rotating rectangular microchannels. Int J Heat Mass Transf 62:184-199

54. Sohankar A, Riahi M, Shirani E (2017) Numerical investigation of heat transfer and pressure drop in a rotating U-shaped hydrophobic microchannel with slip flow and temperature jump boundary conditions. Appl Therm Eng 117:308-321

55. Chiou JP (1982) The effect of nonuniform fluid flow distribution on the thermal performance of solar collector. Sol Energy 29:487-502

Publisher's Note Springer Nature remains neutral with regard to jurisdictional claims in published maps and institutional affiliations. 